\title{
Article
}

\section{Effect of Graphene on Ice Polymorph}

\author{
Chuanbao Zheng ${ }^{1,2,+}\left(\mathbb{D}\right.$, Hao Lu ${ }^{1,+} \oplus$, Quanming Xu ${ }^{1}$, Tianyi Liu ${ }^{1}$, Aniruddha Patil ${ }^{1}$, Jianyang Wu ${ }^{1}$, \\ Renko de Vries ${ }^{2}$, , Han Zuilhof ${ }^{3,4} \mathbb{D}^{-}$and Zhisen Zhang ${ }^{1, *(\mathbb{D}}$
}

1 Research Institute for Biomimetics and Soft Matter, Fujian Provincial Key Laboratory for Soft Functional Materials Research, Department of Physics, Xiamen University, Xiamen 361005, China; chuanbao.zheng@wur.nl (C.Z.); luhao@stu.xmu.edu.cn (H.L.); 19820181154096@stu.xmu.edu.cn (Q.X.); 19820191152993@stu.xmu.edu.cn (T.L.); aniruddhapatil135@mdcollege.in (A.P.); jianyang@xmu.edu.cn (J.W.)

2 Physical Chemistry and Soft Matter, Wageningen University \& Research, Stippeneng 4, 6708 WE Wageningen, The Netherlands; renko.devries@wur.nl

3 Laboratory of Organic Chemistry, Wageningen University \& Research, 6708 WE Wageningen, The Netherlands; han.zuilhof@wur.nl

4 Department of Chemical and Materials Engineering, Faculty of Engineering, King Abdulaziz University, Jeddah 21589, Saudi Arabia

* Correspondence: zhangzs@xmu.edu.cn

$+\quad$ C.Z. and H.L. contributed equally to this manuscript.

Citation: Zheng, C.; Lu, H.; Xu, Q.; Liu, T.; Patil, A.; Wu, J.; de Vries, R.; Zuilhof, H.; Zhang, Z. Effect of Graphene on Ice Polymorph. Crystals 2021, 11, 1134. https://doi.org/ $10.3390 /$ cryst11091134

Academic Editors: Haihui Zhang,

Xunhui Xiong, Huihui Xiong and Yaohui Qu

Received: 18 June 2021

Accepted: 15 July 2021

Published: 18 September 2021

Publisher's Note: MDPI stays neutral with regard to jurisdictional claims in published maps and institutional affiliations.

Copyright: (c) 2021 by the authors. Licensee MDPI, Basel, Switzerland. This article is an open access article distributed under the terms and conditions of the Creative Commons Attribution (CC BY) license (https:// creativecommons.org/licenses/by/ $4.0 /)$.

\begin{abstract}
Recently, ice with stacking disorder structure, consisting of random sequences of cubic ice $\left(\mathrm{I}_{\mathrm{c}}\right)$ and hexagonal ice $\left(\mathrm{I}_{\mathrm{h}}\right)$ layers, was reported to be more stable than pure $\mathrm{I}_{\mathrm{h}} / \mathrm{I}_{\mathrm{c}}$. Due to a much lower free energy barrier of heterogeneous nucleation, in practice, the freezing process of water is controlled by heterogeneous nucleation triggered by an external medium. Therefore, we carry out molecular dynamic simulations to explore how ice polymorphism depends on the lattice structure of the crystalline substrates on which the ice is grown, focusing on the primary source of atmospheric aerosols, carbon materials. It turns out that, during the nucleation stage, the polymorph of ice nuclei is strongly affected by graphene substrates. For ice nucleation on graphene, we find $\mathrm{I}_{\mathrm{h}}$ is the dominant polymorph. This can be attributed to structural similarities between graphene and basal face of $I_{h}$. Our results also suggest that the substrate only affects the polymorph of ice close to the graphene surface, with the preference for $\mathrm{I}_{\mathrm{h}}$ diminishing as the ice layer grows.
\end{abstract}

Keywords: heterogeneous nucleation; ice polymorph; stacking disorder; phase selectivity

\section{Introduction}

Ice nucleation is important in the physical environment and biological systems [1-3]. Thus, it is important to accurately estimate the nucleation rate of ice, which is highly related to polymorph of ice crystalline $[4,5]$. For a long time, hexagonal ice $\left(I_{h}\right)$ was assumed to be the most stable ice phase at atmospheric pressure or below. However, this understanding has been questioned by a large number of reports by computer simulation [5-8] and experiment [9-13] in recent years. In the report of Lupi et al. [5] the stacking-disordered [14] critical ice crystallites are about $14 \mathrm{~kJ} / \mathrm{mol}$ of crystallite more stable than hexagonal ice crystallites (at $230 \mathrm{~K}$ ). In these simulations, homogeneous ice nucleation was considered, but in practice, it is almost impossible to eliminate the influence of impurities or external boundaries on ice nucleation [15,16]. Due to a much lower free energy barrier of heterogeneous nucleation, in practice, the freezing process of water is usually controlled by heterogeneous nucleation. This raises the question to what extent heterogeneous ice nucleation influences the recently discovered preference for stacking-disordered ice.

As the main component of atmospheric aerosols, carbon surfaces can greatly promote heterogeneous ice nucleation [17-19]. The crystallization temperature of ice on the graphite surface has been found to be about $12 \mathrm{~K}$ higher than the temperature for homogeneous ice nucleation $[20,21]$. This stimulated both experimental and molecular dynamics (MD) 
simulations investigation of heterogeneous ice nucleation on graphene/graphite and other carbon surfaces [20,22-24].

However, the issue of how nucleation on carbon surfaces influences the preference for stacking-disordered ice has so far not been addressed. To do so, we conducted MD simulations for a series of heterogeneous ice nucleation/growth processes on different carbon surfaces and found that the carbon surfaces have a strong influence on the local ice polymorphs.

\section{Methods}

Modeling. As shown in Figure 1, ice nucleation was studied on four types of atomic flat carbon surfaces with different lattice structures: Graphene (composed by six ring carbon atom), Oblique-Haeckelite (O-Haeckelite, composed by 5-6-7 ring carbon atom), RectangularHaeckelite (R-Haeckelite, composed by 5-7 ring carbon atom), and Random (all carbon atoms distributed randomly, refer to Figure S1) [25]. The reason behind these specific surfaces is that we aimed to clarify the effect of the hexagonal structure of graphene on the polymorph of ice, compared to the two non-hexagonal Haeckelite structures and an amorphous 2D carbon substrate. Analogous homogeneous ice nucleation (Homo) simulations without any substrate were also carried out as control. The size of the 3D periodic simulation boxes (which contain 15,029 water molecules) are $15.0 \times 14.8 \times 15.0 \mathrm{~nm}^{3}$ for the Graphene system, $16.3 \times 15.3 \times 15.0 \mathrm{~nm}^{3}$ for the O-Haeckelite system, $17.0 \times 15.5 \times 15.0 \mathrm{~nm}^{3}$ for the R-Haeckelite system, $15.0 \times 14.9 \times 15.0 \mathrm{~nm}^{3}$ for the Random system, and $15.0 \times 15.0 \times 15.0 \mathrm{~nm}^{3}$ for the Homo system, respectively.

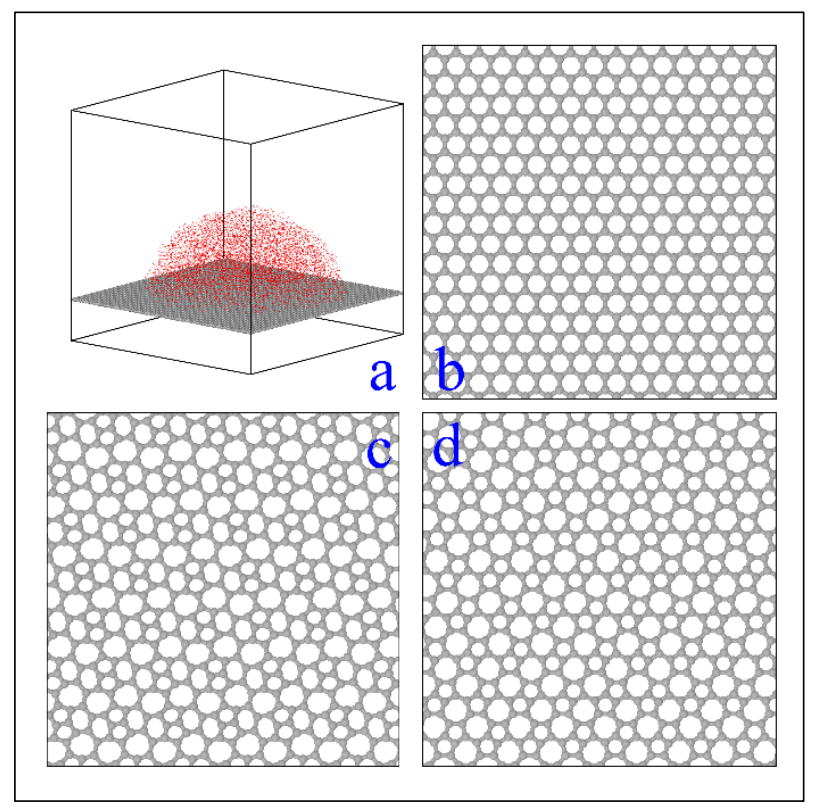

Figure 1. (a) Example of a simulation box. (b-d) show top view (part) of substrates Graphene, $\mathrm{O}$ Haeckelite, and R-Haeckelite, respectively. The top view (part) of substrates Random is shown in Figure S1. Carbon atoms in substrate are portrayed as gray spheres. The water molecules are showed in red dots.

Simulation Details. All MD simulations were performed using large-scale atomic /molecular massively parallel simulator (LAMMPS, Version 5Jun19) package [26]. The coarse-grained mono-atomic $\mathrm{mW}$ water model was applied in all simulations [27]. The interactions between $\mathrm{mW}$ water molecules consist of a sum of pairwise interactions, while the hydrogen bonding between water molecules is represented by three-body contributions, which can nucleate liquid water to ice homogeneously and heterogeneously at a certain supercooling without any advanced sampling method. The $\mathrm{mW}$ model correctly displays the anomalies and structures of liquid water, ices, and amorphous solid water and the transitions between them [28]. The equations of water motion were integrated with the 
velocity Verlet algorithm with a time step of $5 \mathrm{fs}$. All the simulations were conducted in the NVT ensemble. The temperature in the simulation systems was controlled by a Nosé-Hoover thermostat. The same as in previous reports [20], ice nucleation was studied through a cooling ramp of cooling rates of $1 \mathrm{~K} / \mathrm{ns}$, which was chosen after a systematic test of the cooling rates by the authors. To calculate the freezing efficiency [20], $\Delta T_{f}=T_{f}-T_{f}^{\text {homo }}, 40$ independent trajectories were performed for each system. The interactions between water molecules and carbon atoms are taken from the previous report by Lupi' et al. [20], in which water-carbon interaction parameters are: $\sigma_{W C}=0.32 \mathrm{~nm}$ and $\varepsilon_{W C}=0.13 \mathrm{kcal} / \mathrm{mol}$, to reproduce the experimental water contact angle of water on a graphene surface (namely $86^{\circ}$ ) $[29,30]$. All the carbon atoms in the substrates were fixed in all the MD simulations. Water molecules with $\mathrm{I}_{h} / \mathrm{I}_{\mathrm{c}}$ structure were identified using the Chill + algorithm proposed by Nguyen et al. [31], which is available in the OVITO package [32].

\section{Results and Discussion}

To investigate the effect of the substrate lattice structure on the polymorph of ice, MD simulations were employed to study the ice formation process on different substrates: Graphene, Oblique-Haeckelite (O-Haeckelite), Rectangular-Haeckelite (R-Haeckelite), and a Random carbonaceous substrate. As shown in Figure 2, consistent with previous reports $[20,22,33,34]$, after an induction period (during which, the small water clusters with ice structure formed and then disappeared quickly, due to the thermal fluctuation of system), stable ice nuclei (larger than critical size $R_{\mathrm{c}}$ of ice) formed at the water-substrate interface for the systems of Graphene, O-Haeckelite, R-Haeckelite, and Random, which should be due to the much lower heterogeneous nucleation barrier. For these heterogeneous nucleation systems, especially for the nucleation stage, the ice crystals exhibit a single-crystal-like structure with barely any grain boundary, which is due to the 1-dimensional structure match (in the direction perpendicular to the substrate surface) between a flat substrate and a flat crystalline face of ice. While for the Homo system, the new-formed ice exhibits a polycrystalline structure.

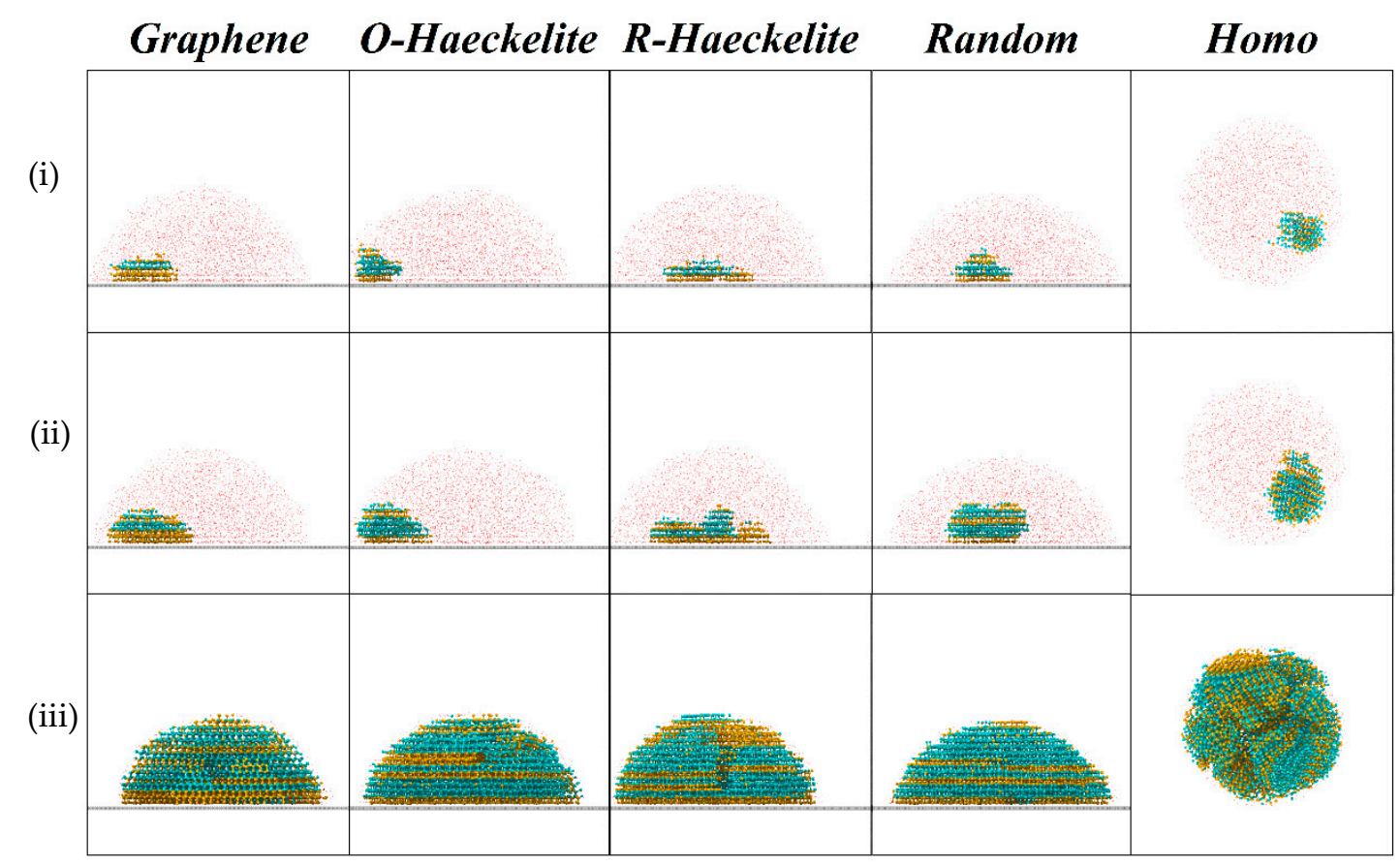

Figure 2. Lateral view of the ice formation procedure from top to bottom: (i) ice nucleation; (ii) ice growth; (iii) water freezing completely. Liquid water is represented by red dots. Water molecules in ice crystallites are represented by colored ball-stick model $\left(\mathrm{I}_{\mathrm{h}}\right.$ : yellow; $\mathrm{I}_{\mathrm{c}}$, cyan). Carbon atoms in substrate are colored gray. 
Intriguingly, for the system of Graphene, the $\mathrm{I}_{\mathrm{h}}$ structure occupies an absolute majority in the ice nuclei during the stage of nucleation. With the growth of ice (after about 5-6 layers of $I_{h}$ formed), the $I_{c}$ turns up, which is consistent with the previous report that the $I_{c}$ grows on $\mathrm{I}_{\mathrm{h}}$ embryos to form a more stable stacking disorder structure [5]. When almost all the liquid water freezes to ice, the percentage of $I_{c}$ is not much different from that of $I_{h}$. While for the systems of O-Haeckelite, R-Haeckelite, Random, and Homo, in all stages of ice formation, the number of water molecules in $\mathrm{I}_{\mathrm{c}}$ is always comparable with the number of water molecules in $\mathrm{I}_{\mathrm{h}}$.

To reveal the phase change process of ice during heterogeneous nucleation processes, the molecular numbers of $I_{c}$ and $I_{h}$ as a function of system temperature (namely simulation time) were extracted from the ice formation MD trajectories (shown Figure 3). The snapshots in Figure 2 share the same trajectories with the results of Figure 3 for each system. As shown in Figure 3a (Graphene system), with the decrease in temperature, the nucleation process was observed in the $\mathrm{I}_{\mathrm{h}}$ ice before the steady growth of $\mathrm{I}_{\mathrm{c}}$. In the growth stage, the $\mathrm{I}_{\mathrm{c}}$ exhibited a lager growth rate than $I_{h}$, leading to an equivalent molecular number of $I_{h}$ and $I_{c}$ at the stage of water freezing completely. While for each of the systems in Figure $3 b-e$, the $I_{c}$ and $I_{h}$ grow simultaneously as the system temperature decreases, indicating that these systems have no selectivity to ice polymorph.

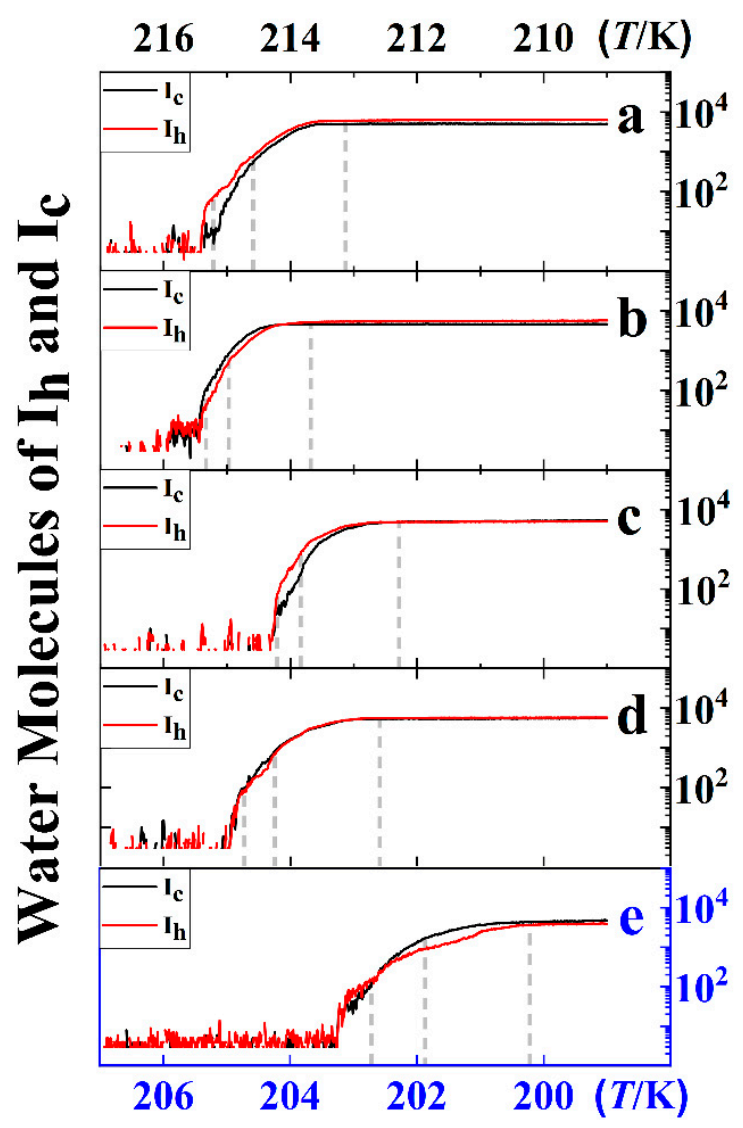

Figure 3. Molecular numbers of water molecules in $\mathrm{I}_{\mathrm{C}}$ and $\mathrm{I}_{\mathrm{h}}$ during a cooling ramp for the systems of (a) Graphene, (b) O-Haeckelite, (c) R-Haeckelite, (d) Random, and (e) Homo. The dashed vertical lines indicate position of snapshots of the ice nucleation, ice growth, and water freezing completely in Figure 2. The blue borders are for panel (e).

To quantitatively reveal the polymorph of ice formed on different substrates, the cubicity [6] (i.e., the proportion of $I_{c}$ ) of the new-formed ices was calculated from the 40 independent MD trajectories for each system (refer to Table 1 and Table S1). As shown in Table 1, the cubicity of ice in the Homo system is $52.5 \pm 1.3 \%, 53.9 \pm 1.6 \%$, and $58.2 \pm 0.7 \%$ for the stage of ice nucleation, ice growth, and water freezing completely, respectively, 
which is consistent with previous reports (about 55\%) [5-7,35]. For ice formed on Graphene, the cubicity is only $28.4 \pm 2.5 \%$ at the nucleation stage, which is significantly lower than that of the Homo system. The results suggest that the graphene substrate has a preferential selectivity to $I_{h}$ over $I_{c}$, which we attribute to the fact that $I_{h}$ (basal face) and graphene share the same hexagonal structure and have a similar lattice structure. The distance between the center of two hexagon rings on graphene surface is $2.46 \AA$ [24,36], and the distance of water molecules in the basal face of $I_{h}$ is $2.76 \AA$ [37,38]. According to previous reports $[24,39,40]$, in the water-graphene system, the center of a hexagon formed by carbon atoms corresponds to the adsorption energy minima positions of water molecules. Due to the similarity of lattice structure between the basal plane of $I_{h}$ and graphene, slight adjustment of the position of interfacial water molecules can match the lattice structure of basal plane of $\mathrm{I}_{\mathrm{h}}$. The calculated mismatch [41] between the substrate and the ice is $10.9 \%$. The ice-nucleating protein, with a mismatch of $10 \%$ to ice, was found to be able to dramatically promote the nucleation of ice [42]. In the report of Bi et al. [24], it was found that the first ice layer on graphene substrate was mainly composed of $\mathrm{I}_{\mathrm{h}}$, while the first ice layer on an amorphous graphene substrate (similar to the O-Haeckelite substrate in this paper) was somewhat messy. The study of Bi et al. also suggests that the similarity between the graphene and the basal face of $\mathrm{I}_{\mathrm{h}}$ results in the selective promotion of the formation of $\mathrm{I}_{\mathrm{h}}$ over $\mathrm{I}_{\mathrm{c}}$. Moreover, in the study of ice formation on $\mathrm{AgI}[43,44]$, it is also found that the substrate lattice structure can alter the polymorph of ice: $\mathrm{I}_{\mathrm{h}}$ mainly observed on the hexagonal $\beta$-AgI, while the Ic mainly found on cubic $\gamma$-AgI. These reports are in good agreement to our MD simulation results, confirming that the formation of $\mathrm{I}_{\mathrm{h}}$ can be selectively promoted by graphene surface.

Table 1. Average cubicity of each simulation system. From top to bottom are the stages of ice nucleation, ice growth, and water freezing completely, respectively.

\begin{tabular}{cccccc}
\hline Substrate & Graphene & O-Haeckelite & R-Haeckelite & Random & Homo \\
\hline & $28.4 \pm 2.5$ & $41.2 \pm 1.9$ & $42.9 \pm 2.3$ & $42.6 \pm 2.8$ & $52.5 \pm 1.3$ \\
Cubicity/\% & $34.2 \pm 2.9$ & $45.2 \pm 4.5$ & $44.0 \pm 3.7$ & $45.5 \pm 3.9$ & $53.9 \pm 1.6$ \\
& $53.4 \pm 1.8$ & $55.3 \pm 1.5$ & $56.5 \pm 1.5$ & $55.0 \pm 1.7$ & $58.2 \pm 0.7$ \\
\hline
\end{tabular}

To further investigate the effect of substrate lattice structure on heterogeneous ice nucleation, freezing efficiency of the substrates, based on the method of Lupi et al. [20], were calculated (shown in Figure 4). It follows that the calculated freezing efficiencies for Graphene, O-Haeckelite, R-Haeckelite, and Random substrates are $12.7 \pm 0.6 \mathrm{~K}, 11.5 \pm 1.2 \mathrm{~K}$, $12.5 \pm 1.0 \mathrm{~K}$, and $11.1 \pm 1.3 \mathrm{~K}$, respectively, which are consistent with the previous reports that the crystallization temperature of ice on the graphite surface is $12 \pm 3 \mathrm{~K}$ higher than the temperature of homogeneous ice nucleation [20,21]. The freezing efficiency of these different substrates has no significant difference, indicating that, although the substrates exhibit different polymorph selectivity of ice, the heterogeneous nucleation promotion effects of the substrates on ice are similar. Moreover, it should be pointed out that the heterogeneous nucleation promotion effect changes with the system temperature [24]. To calculate the freezing efficiency, the system temperature is steadily decreased. The freezing processes are driven by a very high supercooling, which can reduce the heterogeneous nucleation promotion effect. For instance, the heterogeneous ice nucleation rates on different substrates exhibit significant differences only when the system temperature increased to as high as $235 \mathrm{~K}$ [24]. Thus, for a systematic study, e.g., heterogeneous nucleation barrier and heterogeneous nucleation rate, it is necessary to gain more accurate results by taking into account the influence of temperature. Another thing that needs to be specified is that, in our results, the calculated homogeneous nucleation temperature of ice is $1.6 \mathrm{~K}$ higher than that in the previous report [20], which can be attributed to the difference in the number of water molecules between this work and the previous report (refer to Figure S2). According to classic nucleation theory (CNT), the greater the number 
of water molecules in the system, the greater the nucleation probability of ice formation is, which could lead to this $1.6 \mathrm{~K}$ discrepancy.

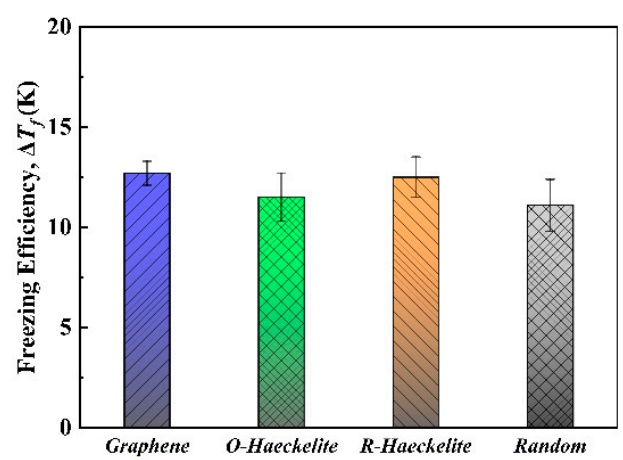

Figure 4. Freezing efficiency of substrates in Graphene, O-Haeckelite, R-Haeckelite, and Random systems.

\section{Conclusions}

MD simulations of heterogeneous ice formation on a series of carbon surfaces show the significant impact of the substrate lattice structure on the polymorph of ice that is formed, but only during the nucleation stage. Specifically, graphene substrates have a preferential selectivity toward the formation of $I_{h}$ over $I_{c}$ during the nucleation stage, due to the similarity between the lattice structure of graphene and $\mathrm{I}_{\mathrm{h}}$. After the nucleation stage the cubicity of new-formed ice increases up to about $53 \%$, due to the higher stability of stacking disordered ice. When subsequently the water freezes completely, the cubicity of ice ranges from $53 \%$ to $58 \%$, in good agreement with homogeneous ice formation and previously reported results. This study enhances our understanding of the surface selectivity mechanism on certain ice polymorphs and provides a unique perspective in the field of crystal growth.

Supplementary Materials: The following are available online at https:/ /www.mdpi.com/article/ 10.3390/cryst11091134/s1. Table S1: Cubicity of the nucleation stage in each simulation trajectory. Figure S1: Surface morphology of 2-dimensional carbon substrate with all the carbon atoms randomly distributed, the Random system. Figure S2: Freezing temperature in Homo-5241 (5241 water molecules) and Homo-15029 (15029 water molecules) systems.

Author Contributions: Conceptualization, C.Z., J.W. and Z.Z.; methodology, C.Z., T.L. and Z.Z.; software, C.Z. and Q.X.; investigation, C.Z. and H.L.; data curation, C.Z., H.L., A.P. and Z.Z.; writingoriginal draft preparation, C.Z., H.L. and Z.Z.; writing—review and editing, C.Z., H.L., R.d.V., H.Z. and Z.Z.; visualization, C.Z., H.L. and Z.Z.; supervision, Z.Z.; project administration, Z.Z.; funding acquisition, J.W. and Z.Z. C.Z. and H.L. contributed equally to this manuscript. All authors have read and agreed to the published version of the manuscript.

Funding: This research was funded by the National Natural Science Foundation of China (Grant Nos. 11904300, 11772278 and 11502221), the Jiangxi Provincial Outstanding Young Talents Program (Grant No. 20192BCBL23029), the Fundamental Research Funds for the Central Universities (Xiamen University: Grant Nos. 20720180014, 20720180018 and 20720180066).

Institutional Review Board Statement: Not applicable.

Informed Consent Statement: Not applicable.

Data Availability Statement: All data generated or analyzed during this study are included in this published article and its additional files.

Acknowledgments: Y. Yu and Z. Xu from Information and Network Center of Xiamen University are acknowledged for the help with the high-performance computer clusters.

Conflicts of Interest: The authors declare no conflict of interest. 


\section{References}

1. Hudait, A.; Moberg, D.R.; Qiu, Y.; Odendahl, N.; Paesani, F.; Molinero, V. Preordering of water is not needed for ice recognition by hyperactive antifreeze proteins. Proc. Natl. Acad. Sci. USA 2018, 115, 8266-8271. [CrossRef] [PubMed]

2. Yan, J.Y.; Patey, G.N. Heterogeneous Ice Nucleation Induced by Electric Fields. J. Phys. Chem. Lett. 2011, 2, 2555-2559. [CrossRef]

3. Herbert, R.J.; Murray, B.J.; Dobbie, S.J.; Koop, T. Sensitivity of liquid clouds to homogenous freezing parameterizations. Geophys. Res. Lett. 2015, 42, 1599-1605. [CrossRef] [PubMed]

4. Hudait, A.; Molinero, V. What Determines the Ice Polymorph in Clouds? J. Am. Chem. Soc. 2016, 138, 8958-8967. [CrossRef] [PubMed]

5. Lupi, L.; Hudait, A.; Peters, B.; Grünwald, M.; Mullen, R.G.; Nguyen, A.H.; Molinero, V. Role of stacking disorder in ice nucleation. Nature 2017, 551, 218-222. [CrossRef] [PubMed]

6. Malkin, T.L.; Murray, B.J.; Salzmann, C.G.; Molinero, V.; Pickering, S.J.; Whale, T.F. Stacking disorder in ice I. Phys. Chem. Chem. Phys. 2015, 17, 60-76. [CrossRef]

7. Moore, E.B.; Molinero, V. Is it cubic? Ice crystallization from deeply supercooled water. Phys. Chem. Chem. Phys. 2011, 13, 20008-20016. [CrossRef]

8. Sosso, G.C.; Tribello, G.A.; Zen, A.; Pedevilla, P.; Michaelides, A. Ice formation on kaolinite: Insights from molecular dynamics simulations. J. Chem. Phys. 2016, 145, 211927. [CrossRef]

9. Thurmer, K.; Nie, S. Formation of hexagonal and cubic ice during low-temperature growth. Proc. Natl. Acad. Sci. USA 2013, 110, 11757-11762. [CrossRef]

10. Kuhs, W.F.; Sippel, C.; Falenty, A.; Hansen, T.C. Extent and relevance of stacking disorder in “ice I(c)". Proc. Natl. Acad. Sci. USA 2012, 109, 21259-21264. [CrossRef]

11. Shilling, J.E.; Tolbert, M.A.; Toon, O.B.; Jensen, E.J.; Murray, B.J.; Bertram, A.K. Measurements of the vapor pressure of cubic ice and their implications for atmospheric ice clouds. Geophys. Res. Lett. 2006, 33, 17. [CrossRef]

12. Hansen, T.C.; Koza, M.M.; Lindner, P.; Kuhs, W.F. Formation and annealing of cubic ice: II. Kinetic study. J. Phys. Cond. Matt. 2008, 20, 285105. [CrossRef]

13. Morishige, K.; Uematsu, H. The proper structure of cubic ice confined in mesopores. J. Chem. Phys. 2005, 122, 44711. [CrossRef] [PubMed]

14. Malkin, T.L.; Murray, B.J.; Brukhno, A.V.; Anwar, J.; Salzmann, C.G. Structure of ice crystallized from supercooled water. Proc. Natl. Acad. Sci. USA 2012, 109, 1041-1045. [CrossRef] [PubMed]

15. Liu, X.Y.; Du, N. Zero-sized effect of nano-particles and inverse homogeneous nucleation. Principles of freezing and antifreeze. J. Biol. Chem. 2004, 279, 6124-6131. [CrossRef] [PubMed]

16. Zhang, Z.; Liu, X.Y. Control of ice nucleation: Freezing and antifreeze strategies. Chem. Soc. Rev. 2018, 47, 7116-7139. [CrossRef]

17. Lary, D.; Shallcross, D.; Toumi, R. Carbonaceous aerosols and their potential role in atmospheric chemistry. J. Geophys. Res. 1999, 104, 15929-15940. [CrossRef]

18. Lupi, L.; Kastelowitz, N.; Molinero, V. Vapor deposition of water on graphitic surfaces: Formation of amorphous ice, bilayer ice, ice I, and liquid water. J. Chem. Phys. 2014, 141, 18C508. [CrossRef]

19. Penner, J.; Eddleman, H.; Novakov, T. Towards the development of a global inventory for black carbon emissions. Atmos. Environ. Part A Gen. Top. 1993, 27, 1277-1295. [CrossRef]

20. Lupi, L.; Hudait, A.; Molinero, V. Heterogeneous nucleation of ice on carbon surfaces. J. Am. Chem. Soc. 2014, 136, 3156-3164. [CrossRef]

21. Lupi, L.; Molinero, V. Does hydrophilicity of carbon particles improve their ice nucleation ability? J. Phys. Chem. A 2014, 118, 7330-7337. [CrossRef]

22. Cabriolu, R.; Li, T. Ice nucleation on carbon surface supports the classical theory for heterogeneous nucleation. Phys. Rev. E 2015, 91, 052402. [CrossRef]

23. Whale, T.F.; Rosillo-Lopez, M.; Murray, B.J.; Salzmann, C.G. Ice nucleation properties of oxidized carbon nanomaterials. J. Phys. Chem. Lett. 2015, 6, 3012-3016. [CrossRef]

24. Bi, Y.; Cabriolu, R.; Li, T. Heterogeneous ice nucleation controlled by the coupling of surface crystallinity and surface hydrophilicity. J. Phys. Chem. C 2016, 120, 1507-1514. [CrossRef]

25. Terrones, H.; Terrones, M.; Hernández, E. New metallic allotropes of planar and tubular carbon. Phys. Rev. Lett. 2000, 84, 1716. [CrossRef]

26. Plimpton, S. Fast parallel algorithms for short-range molecular dynamics. J. Comput. Phys. 1995, 117, 1-19. [CrossRef]

27. Molinero, V.; Moore, E.B. Water Modeled As an Intermediate Element between Carbon and Silicon. J. Phys. Chem. B 2009, 113, 4008-4016. [CrossRef] [PubMed]

28. Johnston, J.C.; Molinero, V. Crystallization, melting, and structure of water nanoparticles at atmospherically relevant temperatures. J. Am. Chem. Soc. 2012, 134, 6650-6659. [CrossRef] [PubMed]

29. Li, H.; Zeng, X.C. Wetting and interfacial properties of water nanodroplets in contact with graphene and monolayer boron-nitride sheets. ACS Nano 2012, 6, 2401-2409. [CrossRef]

30. Adamson, A.W.; Gast, A.P. Physical Chemistry of Surfaces; Interscience: New York, NY, USA, 1967; Volume 15.

31. Nguyen, A.H.; Molinero, V. Identification of Clathrate Hydrates, Hexagonal Ice, Cubic Ice, and Liquid Water in Simulations: The CHILL+ Algorithm. J. Phys. Chem. B 2015, 119, 9369-9376. [CrossRef] 
32. Stukowski, A. Visualization and analysis of atomistic simulation data with OVITO-the Open Visualization Tool. Mod. Simul. Mater. Sci. Eng. 2010, 18, 015012. [CrossRef]

33. Cox, S.J.; Raza, Z.; Kathmann, S.M.; Slater, B.; Michaelides, A. The microscopic features of heterogeneous ice nucleation may affect the macroscopic morphology of atmospheric ice crystals. Faraday Disc. 2013, 167, 389-403. [CrossRef]

34. Xue, H.; Lu, Y.; Geng, H.; Dong, B.; Wu, S.; Fan, Q.; Zhang, Z.; Li, X.; Zhou, X.; Wang, J. Hydroxyl Groups on the Graphene Surfaces Facilitate Ice Nucleation. J. Phys. Chem. Lett. 2019, 10, 2458-2462. [CrossRef]

35. Li, T.; Donadio, D.; Russo, G.; Galli, G. Homogeneous ice nucleation from supercooled water. Phys. Chem. Chem. Phys. 2011, 13, 19807-19813. [CrossRef] [PubMed]

36. Pozzo, M.; Alfe, D.; Lacovig, P.; Hofmann, P.; Lizzit, S.; Baraldi, A. Thermal expansion of supported and freestanding graphene: Lattice constant versus interatomic distance. Phys. Rev. Lett. 2011, 106, 135501. [CrossRef] [PubMed]

37. Liu, J.; Zhu, C.; Liu, K.; Jiang, Y.; Song, Y.; Francisco, J.S.; Zeng, X.C.; Wang, J. Distinct ice patterns on solid surfaces with various wettabilities. Proc. Natl. Acad. Sci. USA 2017, 114, 11285-11290. [CrossRef] [PubMed]

38. Nguyen, A.H.; Koc, M.A.; Shepherd, T.D.; Molinero, V. Structure of the Ice-Clathrate Interface. J. Phys. Chem. C 2015, 119, 41044117. [CrossRef]

39. Zhang, Z.S.; Kang, Y.; Liang, L.J.; Liu, Y.C.; Wu, T.; Wang, Q. Peptide encapsulation regulated by the geometry of carbon nanotubes. Biomaterials 2014, 35, 1771-1778. [CrossRef] [PubMed]

40. Liu, Y.-C.; Shen, J.-W.; Gubbins, K.E.; Moore, J.D.; Wu, T.; Wang, Q. Diffusion dynamics of water controlled by topology of potential energy surface inside carbon nanotubes. Phys. Rev. B 2008, 77, 125438. [CrossRef]

41. Cox, S.J.; Kathmann, S.M.; Purton, J.A.; Gillan, M.J.; Michaelides, A. Non-hexagonal ice at hexagonal surfaces: The role of lattice mismatch. Phys. Chem. Chem. Phys. 2012, 14, 7944-7949. [CrossRef]

42. Qiu, Y.; Hudait, A.; Molinero, V. How Size and Aggregation of Ice-Binding Proteins Control Their Ice Nucleation Efficiency. J. Am. Chem. Soc. 2019, 141, 7439-7452. [CrossRef] [PubMed]

43. Roudsari, G.; Reischl, B.; Pakarinen, O.H.; Vehkamäki, H. Atomistic Simulation of Ice Nucleation on Silver Iodide (0001) Surfaces with Defects. J. Phys. Chem. C 2019, 124, 436-445. [CrossRef]

44. Zielke, S.A.; Bertram, A.K.; Patey, G.N. A Molecular Mechanism of Ice Nucleation on Model AgI Surfaces. J. Phys. Chem. B 2015, 119, 9049-9055. [CrossRef] [PubMed] 